\title{
Use of fascia lata autograft for repair of urinary bladder defect in rabbits
}

\author{
Muhammed Kaan Yonez ${ }^{1}$, Gultekin Atalan ${ }^{1}$, Mehmet Onder Karayigit ${ }^{2}$, Umut Alpman ${ }^{1}$ \\ ${ }^{1}$ University of Erciyes, Faculty of Veterinary Medicine, \\ Department of Surgery, Kayseri, Turkey \\ ${ }^{2}$ University of Cumhuriyet, Faculty of Veterinary Medicine, \\ Department of Pathology, Sivas, Turkey \\ Received August 7, 2018 \\ Accepted February 12, 2019
}

\begin{abstract}
The aim of this study was to investigate the compatibility of a fascia lata autograft for urinary bladder tissue defect, to evaluate the biomechanical, radiographical, macroscopical, biochemical, and histopathological test findings, and early and late complications of the surgical processes in rabbits. Thirty two adult healthy New Zealand rabbits were randomly allocated to 4 different groups of 8 animals. A $2 \times 2 \mathrm{~cm}$ urinary bladder defect was repaired by the same size of fascia lata in experimental groups (Group 1, 2, 3). Rabbits in Group 1, 2 and 3 were euthanized at the end of the $4^{\text {th }}, 8^{\text {th }}$ and $12^{\text {th }}$ week after surgeries, respectively. No surgical procedure was carried out for the urinary bladder of the rabbits in the control group, but their urinary bladders were used for biomechanical tests and the values compared with those of Group 1,2 and 3. Histopathological examination of the grafted area was performed. The grafted area was consistent with that of the tissue of urinary bladder. No significant difference was found between the urinary bladder and the grafted area. No differences in biomechanical tests were recorded between grafted and ungrafted urinary bladders. Histopathologically, fascia lata turned into a normal urinary bladder tissue. Therefore, a fascia lata autograft can be succesfully used in urinary bladder defects. Fascia lata grafts can be used successfully in pathological conditions of the urinary bladder that require a new tissue.
\end{abstract}

Graft, creatine, urea, biomechanic, surgery, urology

Since a better alternative graft material has not been found yet, graft materials obtained from the gastrointestinal tract are accepted as the golden standard despite their complications (Atala 2000; Mahfouz et al. 2013). It has been reported that the rate of complications due to the use of gastrointestinal segments varies between 3\% and 44\% (Nuininga et al. 2004). Various complications of urinary bladder reconstruction based on grafts obtained from intestinal segments have been reported such as chronic bacteriuria, stone formation, growth retardation in bones due to calcium-phosphate metabolism disturbance, gastrointestinal motility disorders, mucus secretion and fluid-electrolyte imbalance (Mahfouz et al. 2013; Abdelrhman et al. 2013).

Recently, biomaterials such as acellular bladder matrix, small intestine submucosa, polyglycolic acid either by themselves or in combination with progenitor cells have started to be used for urinary bladder reconstruction in animal models. Despite the ability of these matrices to support the regeneration of urinary bladder, they have been unsuccessful due to long-term graft contracture, graft rupture and fibrosis formation (Seth et al. 2013).

Fascia is a sheet of thin, wide and soft strips covering tissues, muscle or muscle groups. Fasciae are made up of collagen and elastic fibres that show maximum strength against stretching (Liebich and Konig 2004). Fascia lata (FL) continues as fascia gluteus without interruption and covers the muscles of the outer and anterior of the thigh (Sisson 1911).

In our study, we aimed to evaluate the compatibility, usability, early and late complications of using autogenous FL graft in the treatment of experimentally induced defects of the urinary bladder.

Address for correspondence:

Dr. Muhammed Kaan Yonez

Department of Surgery

Faculty of Veterinary Medicine

University of Erciyes, 38039 Turkey.

Phone: +905534858558

Email: kaanyonez@gmail.com

http://actavet.vfu.cz/ 


\section{Materials and Methods}

\section{Animals}

A total of thirty-two New Zealand male rabbits aging between 10-12 months and weighing mean $2.089 \pm 0.52 \mathrm{~kg}$ were used in this study. The rabbits were subjected to preliminary clinical examinations and found to be healthy.

The ethical approval of this study was granted by the ethics approval process of the University of Erciyes's Local Ethics Department on Animal Experiments (Date: January14, 2015, Approval no. 14/15).

\section{Groups}

Thirty two adult healthy New Zealand rabbits were randomly allocated into four different groups of eight animals. The FL grafts were applied to defects in the urinary bladders of the rabbits in the experimental groups (Group 1, 2, 3). All rabbits in Group 1, Group 2, and Group 3 were euthanized at the end of the $4^{\text {th }}, 8^{\text {th }}$, and $12^{\text {th }}$ week, respectively. Eight healthy rabbits in the control group were euthanized without any surgeries in the urinary bladder at the end of the $12^{\text {th }}$ week. The control urinary bladder biomechanical test results were compared with the results obtained from experimental groups.

\section{Anaesthesia}

For each rabbit, $5 \mathrm{mg} / \mathrm{kg}$ xylazine-HCL as a pre-anaesthetic agent and $35 \mathrm{mg} / \mathrm{kg}$ ketamine-HCL for induction were administered intramuscularly (IM). Anaesthesia was continued throughout the operation with $2-3 \%$ sevoflurane.

\section{Surgical procedures}

Rabbits were placed on the operation table in left lateral recumbency. A 4-5 cm skin incision was carried out on the lateral thigh and the FL was reached. A FL graft measuring $2 \times 2 \mathrm{~cm}$ was bluntly separated and harvested with surgical scissors (Plate IV, Fig. 1). After obtaining the FL graft, a median laparotomy line was performed for each rabbit and the urinary bladder taken out from abdomen. The most nonvascular area was identified in the corpus region of the urinary bladder for creation of defect. The stay sutures were made with 3-0 polypropylene in the directions of 3, 6 (caudal of bladder), 9, 12 (cranial of bladder) o'clock in order to be able to identify the region where the FL graft was applied (Plate IV, Fig. 2A). A simple continuous suture technique with a 4-0 polydioxanone was applied to the FL graft placed edge to edge with the bladder (Fig. 2B,C). The sutures were applied full thickness into the bladder lumen. The urethral catheter was applied to the urinary bladder and $30 \mathrm{ml} 0.9 \% \mathrm{NaCl}$ solution were administered to check for any leakage (Fig. 2D). The abdominal wall was routinely closed.

\section{Postoperative care}

Immediately prior to the operation and during the postoperative period, animals were treated with ceftriaxone at a dose of $100 \mathrm{mg} / \mathrm{kg}$ IM for infection prophylaxis. All animals were also administered butorphanol at $0.3 \mathrm{mg} / \mathrm{kg}$ subcutaneously (SC) $24 \mathrm{~h}$ prior to surgery and once daily for 2 days following surgery.

\section{Radiographic analysis}

A urethral catheter was placed for positive contrast radiography for each rabbit under sedation with xylazine $(5 \mathrm{mg} / \mathrm{kg} \mathrm{IM})$ and latero-lateral and ventro-dorsal radiographs were taken on the $3^{\text {rd }}$ day postoperatively and before the euthanasia. For positive contrast cystography, $20 \mathrm{ml}$ of urinary system contrast material (Urografin $76 \%$, Bayer, Kiel, Germany) were applied from the urethral catheter.

\section{Biochemical analysis}

Before the operation, on the third postoperative day and just before the euthanasia, $2 \mathrm{ml}$ blood were taken into tubes from the vena auricularis lateralis. Serum blood urea nitrogen (BUN) and creatine values obtained from rabbits were measured.

\section{Macroscopic examination}

Prior to euthanasia, the grafted region was viewed macroscopically for revealing graft tissue colour, wall thickness, graft rejection, adhesions, oedema, stone formation, necrosis, urine leakage and inflammation. Furthermore, inflammation was graded from 0 to 3 degree as follows: 0 - no inflammation, 1 - mild inflammation (mild red colour, mild thickness, poor vessel formation), 2 - moderate inflammation (moderate red colour, moderate tissue thickness, apparent moderate vessel formation), and 3 - severe inflammation (apparent red tissue colour, strong tissue thickness and apparent several vessel formation).

\section{Euthanasia}

At the end of the study, rabbits in all groups were given Na-pentobarbital at an intravenous (IV) dose of $100 \mathrm{mg} / \mathrm{kg}$ and euthanasia was performed following routine anaesthesia protocols.

Biomechanical testing

The received samples were subjected to biomechanical testing on the Tensile-Press device (Shimadzu Ag-Xd 
$50 \mathrm{kn}$, Kyoto, Japan). The specimens were placed in the mutual clamps of the device and a force was applied at a speed of $5 \mathrm{~mm} / \mathrm{min}$.

\section{Histopathological and immunohistochemical analysis}

In the histopathological examination, sections were stained with haematoxylin and eosin (HE) to view the grafted area. At the immunohistochemical examination, sections were stained with alfa smooth actin (Thermo Scientific, MS-113-PO, USA) and cytokeratin (Thermo Scientific, MS-343-PO, USA) primer antibody to investigate the formation of newly formed smooth muscle and epithelial tissue.

\section{Statistical analysis}

The data was evaluated in the IBM SPSS Statistics 22.0 statistical package program. The descriptive statistics were given as the number of units $(\mathrm{n})$, mean \pm standard deviation $(\bar{x} \pm \mathrm{SD})$, median (min-max). Cross-group comparisons were made by One-Way ANOVA on normal dividing variables. Inter-temporal comparisons in each group were performed with One-Way Repeated Variance Analysis in the case of normal distribution of differences. A value of $P<0.05$ was considered significant.

\section{Postoperative findings}

\section{Results}

All rabbits in the groups survived during the follow-up period. There was no obvious lameness in the right leg. Urination complications like dysuria, pain, incontinence and urinary difficulty were not observed.

\section{Macroscopic findings}

During urinary bladder removal from the abdomen for macroscopic examination, omental adhesion in three rabbits (Group 1,2,3) and adhesion to the intestine in one rabbit in Group 1 (Plate V, Fig. 3A,B) were noted. It was found that the adhesions were held in only one or two stay sutures, rather than the whole grafted area. Adhesions were easily dissected with a slight pull.

Table 1. Inflammation grades in the groups.

\begin{tabular}{lcc}
\hline Group & $\mathrm{n}$ & $\begin{array}{c}\text { Inflamation grade } \\
\text { median (min-max) }\end{array}$ \\
\hline Group 1 & 8 & $2(1-2)$ \\
Group 2 & 8 & $0(0-1)$ \\
Group 3 & 8 & $0(0-0)$ \\
\hline
\end{tabular}

It was determined that all rabbits had a full urinary bladder with urine and there was no leakage from the graft site when light pressure was applied by hand. The stay sutures were fully available in all of the rabbits in the experimental groups (Group 1, 2, 3). The FL graft was completely fused with the urinary bladder. The findings for the inflammation grades of the groups are given in Table 1.

In two of the rabbits in Group 1, stone formation of 2-3 $\mathrm{mm}$ in diameter was detected attached to the stay sutures (Plate V, Fig. 4A). A free-standing stone (1-1.5 cm in diameter) was noticed in two of the rabbit urinary bladders in Group 2. Similarly, a free-standing stone (1.5-2 cm in diameter) was observed in one of the rabbit urinary bladders in Group 3 (Fig. 4B).

Table 2. Comparison of biomechanical test results among groups.

\begin{tabular}{|c|c|c|c|c|c|}
\hline & $\mathrm{n}$ & $\begin{array}{c}\text { Tensile forces (mPA) } \\
\bar{x} \pm \mathrm{SD}\end{array}$ & $P$ & $\begin{array}{c}\text { Elongation (mm) } \\
\bar{x} \pm \mathrm{SD}\end{array}$ & $P$ \\
\hline Group 1 & 8 & $0.256 \pm 0.09$ & & $17.90 \pm 1.59$ & \\
\hline Group 2 & 8 & $0.382 \pm 0.19$ & 0.478 & $6.49 \pm 0.17$ & 0.081 \\
\hline Group 3 & 8 & $0.347 \pm 0.18$ & & $11.2 \pm 0.82$ & \\
\hline Control group & 8 & $0.296 \pm 0.19$ & & $8.20 \pm 0.47$ & \\
\hline
\end{tabular}

mPA - Megapascal (Newton/ Millimeter square); $P<0.05$ - significant; $\bar{x} \pm \mathrm{SD}$ - mean \pm standard deviation. 


\section{Biomechanical test findings}

The results obtained from the biomechanical tests of the experimental and control groups are given in Table 2 .

There was no significant difference among the groups in terms of the mean of tensile forces of biomechanical test samples $(P>0.05)$. Furthermore, it was macroscopically observed that the samples ruptured from the portion of the normal urinary bladder tissue rather than the graft region of the samples during biomechanical testing (Plate VI, Fig. 5).

\section{Biochemical analysis findings}

No significant difference was found between groups in BUN and creatine levels $(P>0.05)$ (Tables 3, 4).

Table 3. Intra-group comparison of BUN level.

\begin{tabular}{lccccc}
\hline & $\mathrm{n}$ & $\begin{array}{c}\text { BUN Day 0 } \\
(\mathrm{mg} / \mathrm{dl})\end{array}$ & $\begin{array}{c}\text { BUN Day 3 } \\
(\mathrm{mg} / \mathrm{dl})\end{array}$ & $\begin{array}{c}\text { BUN BE } \\
(\mathrm{mg} / \mathrm{dl})\end{array}$ & $\bar{x} \pm \mathrm{SD}$ \\
\hline Group 1 & 8 & $19.73 \pm 6.57$ & $19.16 \pm 4.17$ & $20.22 \pm 4.52$ & 0.753 \\
Group 2 & 8 & $20.20 \pm 3.07$ & $16.71 \pm 3.14$ & $17.66 \pm 4.01$ & 0.077 \\
Group 3 & 8 & $19.40 \pm 2.36$ & $19.37 \pm 1.99$ & $17.66 \pm 1.66$ & 0.170 \\
\hline
\end{tabular}

BUN - blood urea nitrogen; Day 0 - before surgery; Day 3 - $3^{\text {rd }}$ postoperative day; BE - before euthanasia; $\mathrm{n}$ number of units; $P<0.05$ - significant; $\bar{x} \pm \mathrm{SD}$ - mean \pm standard deviation.

Table 4. Intra-group comparison of creatine level.

\begin{tabular}{lccccc}
\hline Group & $\mathrm{n}$ & $\begin{array}{c}\text { Creatine } \\
\text { Day } 0(\mathrm{mg} / \mathrm{dl}) \\
\bar{x} \pm \mathrm{SD}\end{array}$ & $\begin{array}{c}\text { Day } 3(\mathrm{mg} / \mathrm{dl}) \\
\bar{x} \pm \mathrm{SD}\end{array}$ & $\begin{array}{c}\mathrm{BE}(\mathrm{mg} / \mathrm{dl}) \\
\bar{x} \pm \mathrm{SD}\end{array}$ & $P$ \\
\hline Group 1 & 8 & $0.93 \pm 0.21$ & $0.83 \pm 0.18$ & $0.82 \pm 0.15$ & 0.095 \\
Group 2 & 8 & $0.83 \pm 0.20$ & $0.86 \pm 0.17$ & $0.91 \pm 0.19$ & 0.663 \\
Group 3 & 8 & $0.86 \pm 0.20$ & $0.88 \pm 0.12$ & $0.87 \pm 0.12$ & 0.955 \\
\hline
\end{tabular}

Day 0 - before surgery; Day 3 - $3^{\text {rd }}$ postoperative day; BE - before euthanasia; $\mathrm{n}$ - number of units; $P<0.05$ significant; $\bar{x} \pm \mathrm{SD}$ - mean \pm standard deviation.

\section{Radiographic findings}

When the radiographs were evaluated at the $3^{\text {rd }}$ day postoperatively and before euthanasia, none of the rabbits had any leakage through the graft site. All the radiographs showed that the lines were smooth, the lumen was completely filled with contrast material and images were similar to those of the normal urinary bladder anatomy. (Plate VI, Fig. 6A,B).

\section{Histopathological findings}

Examination using the HE staining method revealed that there was an excessive amount of vessel increase between the collagenous tissues in the samples of Group 1 (Plate VII, Fig. 7A). In the samples from Group 2 and Group 3, vessel density was similar to that of a normal urinary bladder (Plate VII, Fig. 7B,C).

At the examination using the cytokeratin staining method, all samples of Group 1, Group 2 and Group 3 were observed to be covered with transitional epithelium on the surface of the graft site facing the urinary bladder lumen. It was determined that the epithelial tissue in Group 1 was irregularly shaped compared to the normal urinary bladder epithelium, 
whereas it could not be distinguished from the normal urinary bladder epithelium in Groups 2 and 3 (Plate VIII, Fig. 8A,B,C).

During the examination using alpha smooth actin staining, newly formed smooth muscle formations sprinkled between the collagen fibres were observed in the graft region at the samples of Group 1 (Plate IX, Fig. 9A). In the samples of Group 2, it was seen that newly formed smooth muscle formations were almost in the same order as collagenous tissue (Plate IX, Fig. 9B). Examination of the samples of Group 3 revealed that newly formed smooth muscle formations were spreading more intensely, and collagenous tissue was spread between smooth muscles as a residue (Plate IX, Fig. 9C).

\section{Discussion}

In our study, bladder defects were repaired by autogenous FL grafts. To the best of the authors' knowledge, there no other study using FL grafts for the reconstruction of the urinary bladder can be found in the literature.

A variety of graft materials were used in bladder reconstructive studies. The studies have reported that majority of deaths occurred due to urinary leakage which caused uraemia (Kajbafzadeh et al. 2012), urinary bladder rupture (Obara et al. 2006), and postoperative infection (Hattori et al. 2006). In the present study, none of the rabbits died during the intraoperative and postoperative periods. During postoperative weeks 4, 8, and 12, no signs of deterioration, weight loss, weakness or infection were observed in the general state of the rabbits. In addition, in the biochemical analysis of blood taken on the third postoperative day and before euthanasia, BUN and creatine values were within the reference values range reported by Hewitt et al. (1989). In the context of biochemical and positive contrast cystography results, it is understood that no leakage occurred between the urinary bladder and the graft material and did not cause any abnormality in the renal function. In our study, the fact that no leakage was observed is believed to be due to the shaping of the FL texture based on the good adaptation and hence integration with the bladder tissue.

Ryan et al. (1971) reported that as a result of abdominal adhesions due to inflammation caused by damage to serosal surfaces, fibrinogen leaked into the region and then transformed into fibrin clots. They also stated that when fibrin clots come in contact with other organs, they might form an adhesion. We believe that the root cause of adhesions is due to either blood clots leaked from the veins in the region as a result of the incision made to create a defect in the urinary bladder, or the fibrin clots formed to close the gap between the graft and the urinary incision which contacted with other organs, as reported by Ryan et al. (1971).

One of the most common complications related to the use of intestinal segments in the urinary bladder is stone formation (Kumar and Jayant 2014). Khoury et al. (1997) reported that the mucus secreted from the intestinal segment plays an important role in stone formation by acting as a kernel. Fascia is completely composed of collagen fibres. Therefore, it does not possess features such as secretion of mucus. Monsour et al.(1987) who utilized synthetic collagen-vicryl membrane grafts in the rabbit urinary bladder, used a non-absorbable suture material for the identification in one group, and a fully absorbable suture material for the other group. As a result, they determined that out of the rabbits with observed stones, 6 of them belonged to the group in which the non-absorbable suture material was applied and only 1 of them belonged to the group in which the suture material of the absorbable suture was applied. Mons our et al.(1987) reported that the postoperative stone formation was due to the suture material applied to detect the postoperative operative site which acted as a core for stone formation. Morris et al. (1986) assessed the stone formation in urinary bladders of cystotomized rabbits by applying chromic catgut, polydioxanone and polypropylene suture materials. Similarly, Kaminski et al. (1978), Morris et al. (1986), Hanke et al. (1994) considered an increased risk of stone formation 
due to the use of non-absorbable suture materials in the urinary bladder. In our study, we think that the stone formation depends on the use of non-absorbable suture material which we applied with a range of $90^{\circ}$ for the graft site to be identified. In this respect, our study is in parallel with studies of Kaminski et al. (1978), Morris et al. (1986), Monsour et al. (1987), and Hanke et al. (1994).

Arnold et al. (2009) compared biomechanical test results of single-ply and multi-ply small bowel submucosa, dog FL, and propylene mesh graft materials in their study. They reported based on all of the test results that FL was stronger than the other materials. Since all of the fractures in our study were performed in normal urinary bladder tissue, it was not possible to determine the tensile stress of the fascia tissue. This could be noted as an evidence that the tensile strength of the fascia tissue is much higher than that of the urinary bladder. The fact that the ruptures did not occur at the suture line between the urinary bladder and the graft shows that the applied FL graft fitted the urinary bladder completely.

The FL as a graft material has been successfully used in the closure of urethral defects (Atalan et al. 2005; Sade et al. 2007), in urethral fistulas (Ayyildiz et al. 2006), in the treatment of urinary incontinence (Griebling et al. 1998), and in the reconstruction of FL grafts obtained from cadavers (Rabah et al. 2004) where successful results have been reported. In our study, FL applied to urinary bladder defects did not cause any complications during or after the surgery.

From the viewpoint of the urothelium tissue, the area of graft application could not be distinguished from the normal urinary bladder wall. Sutherland et al. (1996) reported the formation of urothelium on the fourth day, Probst et al. (1997) in the first postoperative week, Sade et al. (2007) on the tenth postoperative day, Nuininga et al. (2004) in the second postoperative week and Hattori et al. (2006) in the fourth postoperative week. In our study, the entire lumen of the region with grafts in HE and cytokeratin staining was observed in all of the groups. The newly formed urothelium in the region of the graft had covered the entire lumen as a whole with the normal urinary bladder.

While it was reported that the smooth muscle formation was observed at week 1 by Probst et al. (1997), at week 2 by Sutherland et al. (1996) and Nuininga et al. (2004) and at week 12 by Rabah et al. (2002), Ayyildiz et al. (2006) and Hattori et al. (2006) reported that smooth muscle formation was inadequate. Since the first group was euthanized at the end of week 4, we do not know exactly when smooth muscle regeneration began. However, unlike Rabah et al. (2002), Hattori et al. (2006), and Ayyildiz et al. (2006), smooth muscle formation was observed in our study between the collagenous tissues at the end of the fourth week. We were not able to observe the complete conversion of the fascia tissue to smooth muscle cells since our study ended at the $12^{\text {th }}$ week. Perhaps if the study is carried out for a longer period of time, it would be possible to say whether the FL tissue completely converts into the urinary bladder smooth muscle tissue.

In general, as a result of clinical, radiological and histopathological evaluations, a FL graft could replace urinary bladder tissue. The findings obtained in our study will contribute to clinical practice in reconstructive urology.

\section{Acknowledgement}

This study was supported by Erciyes University Scientific Research Projects Unit project number TDK-20166356.

\section{References}

Abdelrhman MA, Seddek AM, Bakr HA, Elnesr KA 2013: Full-thickness hysterocystoplasty for management of a large bladder defect: experimental study in goats. J Vet Med Sci 75: 767-771

Arnold GA, Mathews KG, Roe S, Mente P, Seaboch T 2009: Biomechanical comparison of four soft tissue replacement materials: an in vitro evaluation of single and multilaminate porcine small intestinal submucosa, canine fascia lata, and polypropylene mesh. Vet Surg 38: 834-844

Atala A 2000: Tissue engineering for bladder substitution. World J Urol 18: 364-370 
Atalan G, Cihan M, Sozmen M, Ozaydin I 2005: Repair of urethral defects using fascia lata autografts in dogs. Vet Surg 34: 514-518

Ayyildiz A, Celebi B, Akgul KT, Nuhoglu B, Caydere M, Germiyanoglu C 2006: A comparison of free skin graft, fascia lata, alloderm, bovine pericardium and primary repair in urethrocutaneous fistulas without diversion: an experimental study. Pediatr Surg Int 22: 809-814

Griebling TL, Berman CJ, Kreder KJ 1998: Fascia lata sling cystourethropexy for the management of female urinary incontinence. Int Urogynecol J 9: 165-173

Hanke PR, Timm P, Falk G, Kramer W 1994: Behavior of different suture materials in the urinary bladder of the rabbit with special reference to wound healing, epithelization and crystallization. Urol Int 52: 26-33

Hattori K, Joraku A, Miyagawa T, Kawai K, Oyasu R, Akaza H 2006: Bladder reconstruction using a collagen patch prefabricated within the omentum. Int J Urol 13: 529-537

Hewitt CD, Innes DJ, Savory J, Wills MR 1989: Normal biochemical and hematological values in New Zealand white rabbits. Clin Chem 35: 1777-1779

Kajbafzadeh AM, Esfahani SA, Sadeghi Z, Elmi A, Monajemzadeh M 2012: Application of different scaffolds for bladder wall regeneration: the bladder as a natural bioreactor. Tissue Eng Part A 18: 882-887

Kaminski JM, Katz AR, Woodward SC 1978: Urinary bladder calculus formation on sutures in rabbits, cats and dogs. Surg Gynecol Obstet 146: 353-357

Khoury AE, Salomon M, Doche R, Soboh F, Ackerley C, Jayanthi R, McLorie GA, Mittelman MW 1997: Stone formation after augmentation cystoplasty: the role of intestinal mucus. J Urol 158: 1133-1137

Kumar S, Jayant K 2014: Massive vesical calculi formation as a complication of augmentation cystoplasty. Nephrourol Mon 7: 1-3

Liebich HG, Konig HE 2004: General Introduction. In: Konig HE, Liebich HG (Eds): Veterinary Anatomy of Domestic Mammals Textbook and Colour Atlas. $3^{\text {rd }}$ edn. Schattauer, Stuttgart, pp. 1-26

Mahfouz W, Elsalmy S, Corcos J, Fayed AS 2013: Fundamentals of bladder tissue engineering. Afr J Urol 19: $51-57$

Monsour MJ, Mohammed R, Gorham SD, French DA, Scott R 1987: An assessment of a collagen/vicryl composite membrane to repair defects of the urinary bladder in rabbits. Urol Res 15: 235-238

Morris MC, Baquero A, Redovan E, Mahoney E, Bannett AD 1986: Urolithiasis on absorbable and non-absorbable suture materials in the rabbit bladder. J Urol 135: 602-603

Nuininga JE, van Moerkerk H, Hanssen A, Hulsbergen CA, Oosterwijk-Wakka J, Oosterwijk E, de Gier RP, Schalken JA, van Kuppevelt TH, Feitz WF 2004: A rabbit model to tissue engineer the bladder. Biomaterials 25: $1657-1661$

Obara T, Matsuura S, Narita S, Satoh S, Tsuchiya N, Habuchi T 2006: Bladder acellular matrix grafting regenerates urinary bladder in the spinal cord injury rat. Urology 68: 892-897

Probst M, Dahiya R, Carrier S, Tanagho EA 1997: Reproduction of functional smooth muscle tissue and partial bladder replacement. Br J Urol 79: 505-515

Rabah DM, Begin LR, Zahran A, Corcos J 2004: Tissue reactions of the rabbit urinary bladder to cadaveric human fascia lata and polypropylene surgical mesh. Can J Urol 11: 2344-2349

Rabah DM, Spiess PE, Begin LR, Corcos J 2002: Tissue reaction of the rabbit urinary bladder to tension-free vaginal tape and porcine small intestinal submucosa. BJU Int 90: 601-606

Ryan GB, Grobéty J, Majno G 1971: Postoperative peritoneal adhesions: a study of the mechanisms. Am J Pathol 65: $117-148$

Sade C, Ugurlu K, Ozcelik D, Huthut I, Ozer K, Ustundag N, Saglam I, Bas L 2007: Reconstruction of the urethral defects with autologous fascial tube graft in a rabbit model. Asian J Androl 9: 835-842

Seth A, Chung YG, Gil ES, Tu D, Franck D, Di Vizio D, Adam RM, Kaplan DL, Estrada CRJ, Mauney JR 2013: The performance of silk scaffolds in a rat model of augmentation cystoplasty. Biomaterials 34: 4758-4765

Sisson S 1911: Textbook Of Veterinary Anatomy, $1^{\text {st }}$ edn, WB Saunders, Philadelphia, 943 p.

Sutherland RS, Baskin LS, Hayward SW, Cunha GR 1996: Regeneration of bladder urothelium, smooth muscle, blood vessels and nerves into an acellular tissue matrix. J Urol 156: 571-577 
Plate IV

Yonez M. K. et al.: Use of fascia ... pp. 57-63

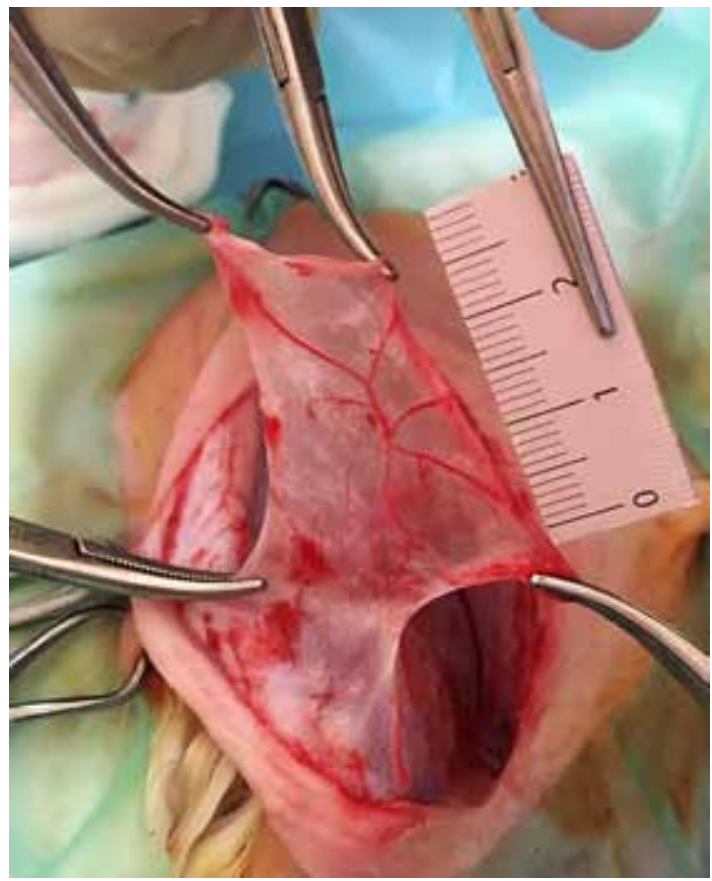

Fig. 1. Taking of $2 \times 2 \mathrm{~cm}$ size graft from fascia lata

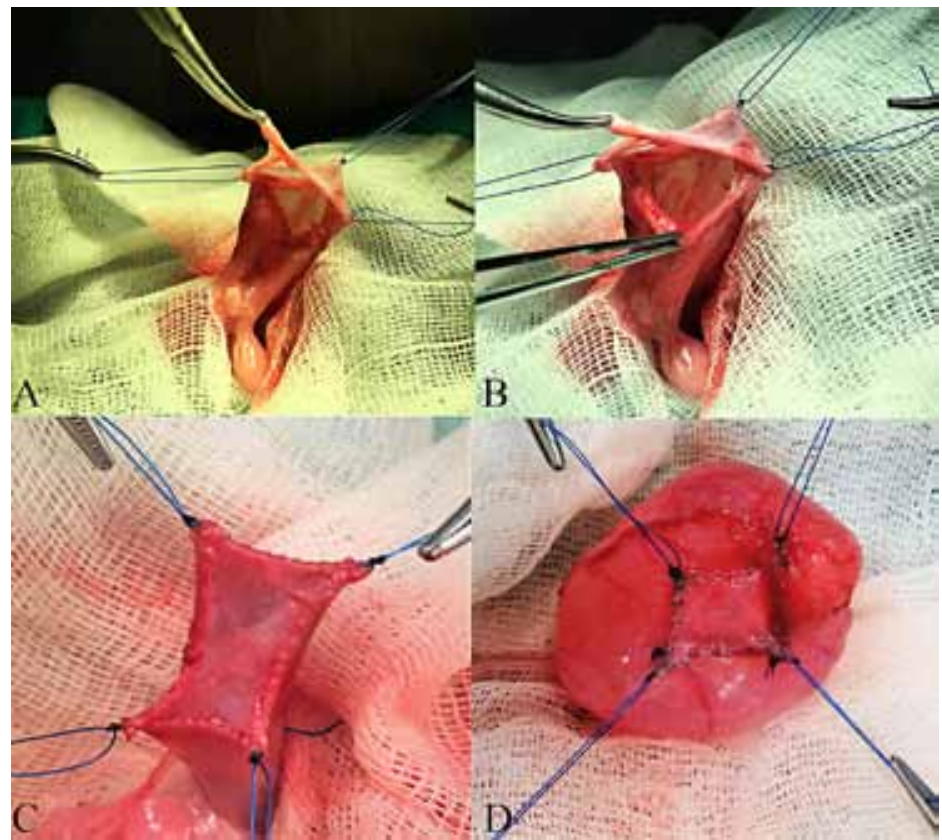

Fig. 2A. Application of stay sutures. 2B. $2 \times 2 \mathrm{~cm}$ size defect formation in urinary bladder. 2 C. Suturing of fascia lata graft to urinary bladder defect. 2D. Control of leakage from the graft site 


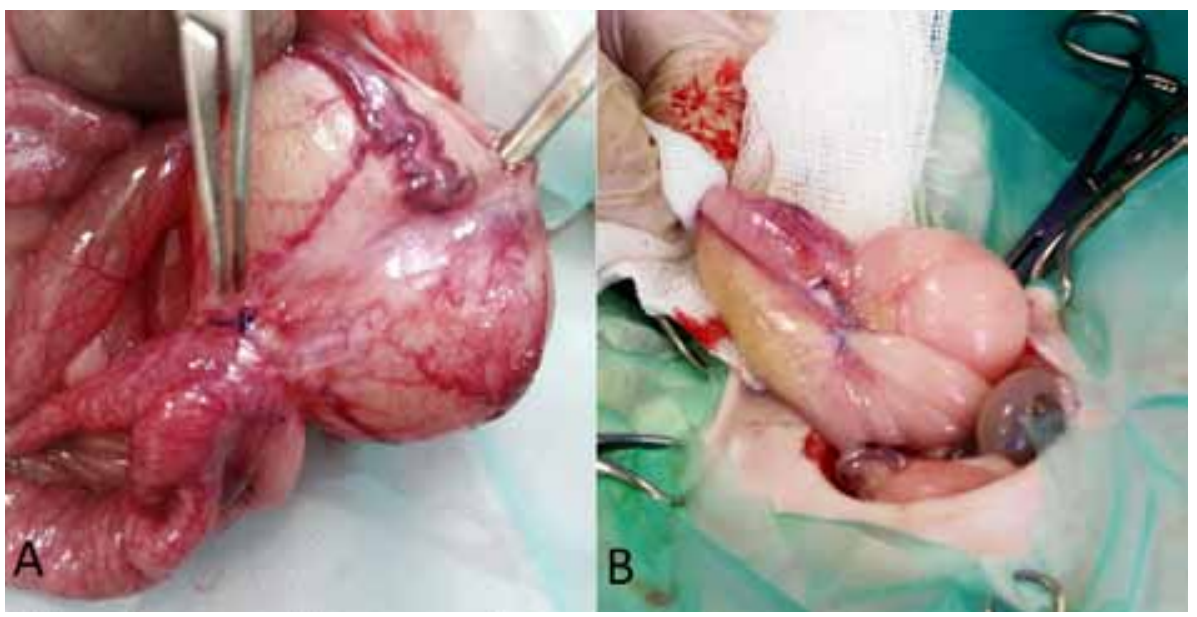

Fig. 3A. Intestinal adhesion to stay sutures in the graft site (Group 1). 3B. Omentum adhesion to stay sutures in the graft site (Group 2)

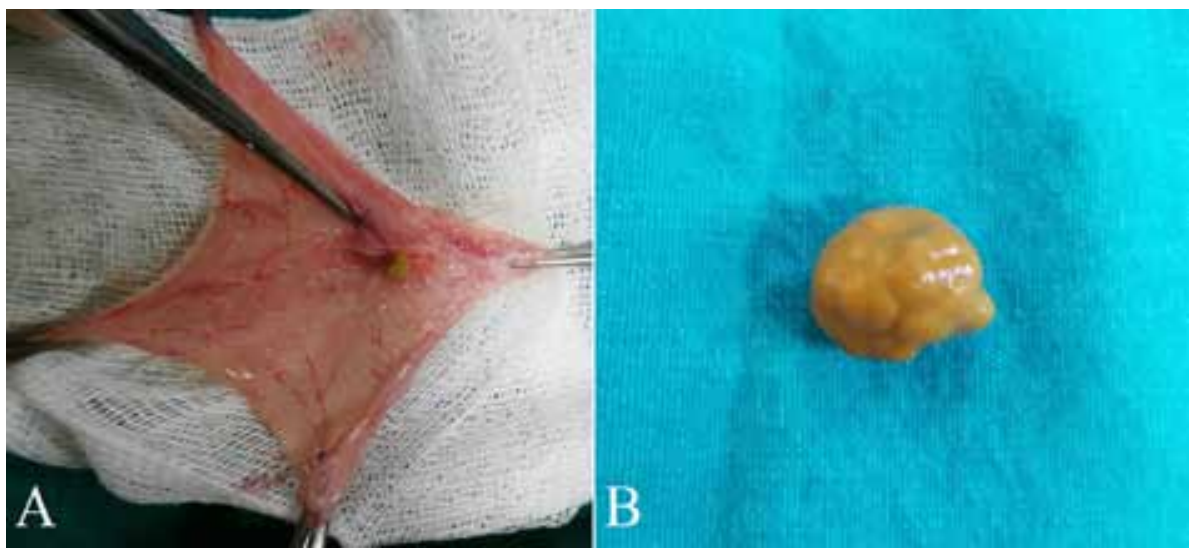

Fig. 4A. Adhesive stone formation in stay sutures (Group 1). 4B. Stone removed from the urinary bladder (Group 3) 
Plate VI

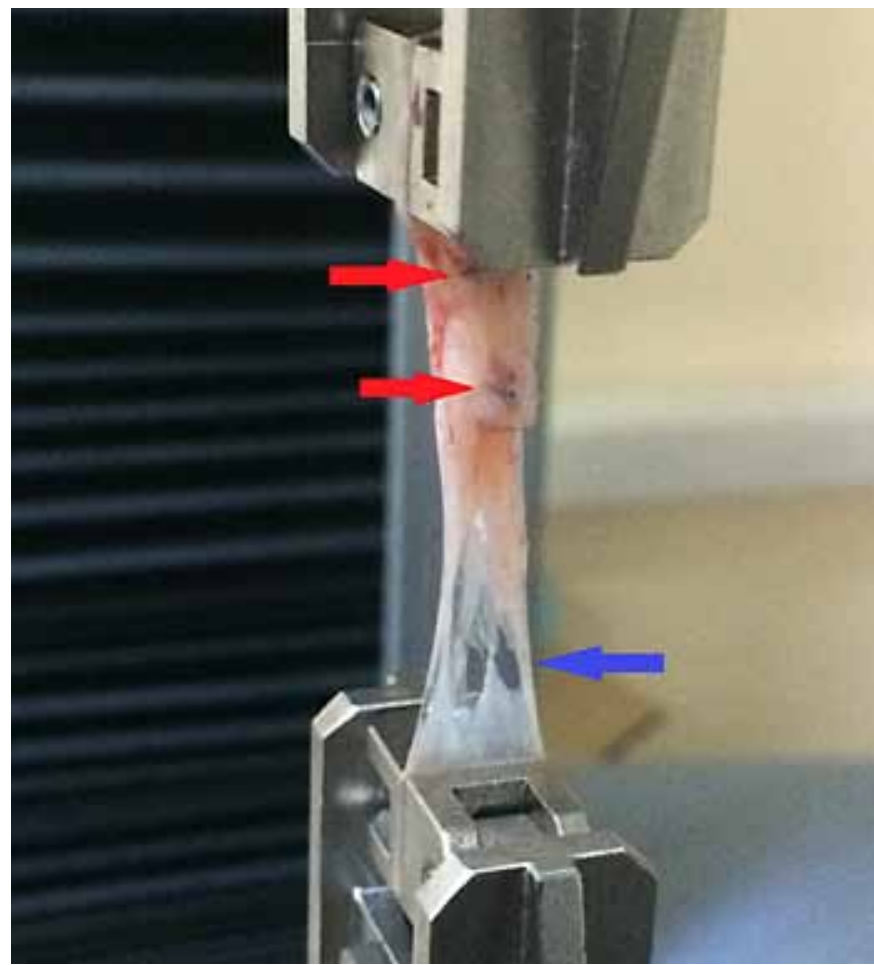

Fig. 5. Biomechanical testing (red arrows: graft area; blue arrow: rupture area)

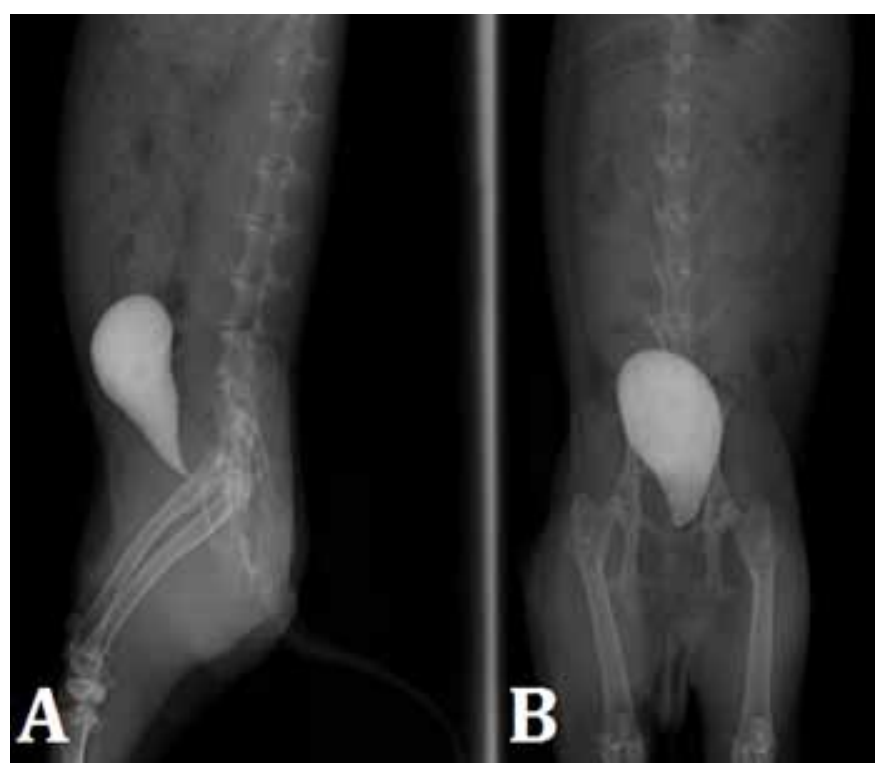

Fig. 6A,B. Radiographs of the grafted region before euthanasia (Group 1). A: Latero-lateral position. B: Ventro-dorsal position 

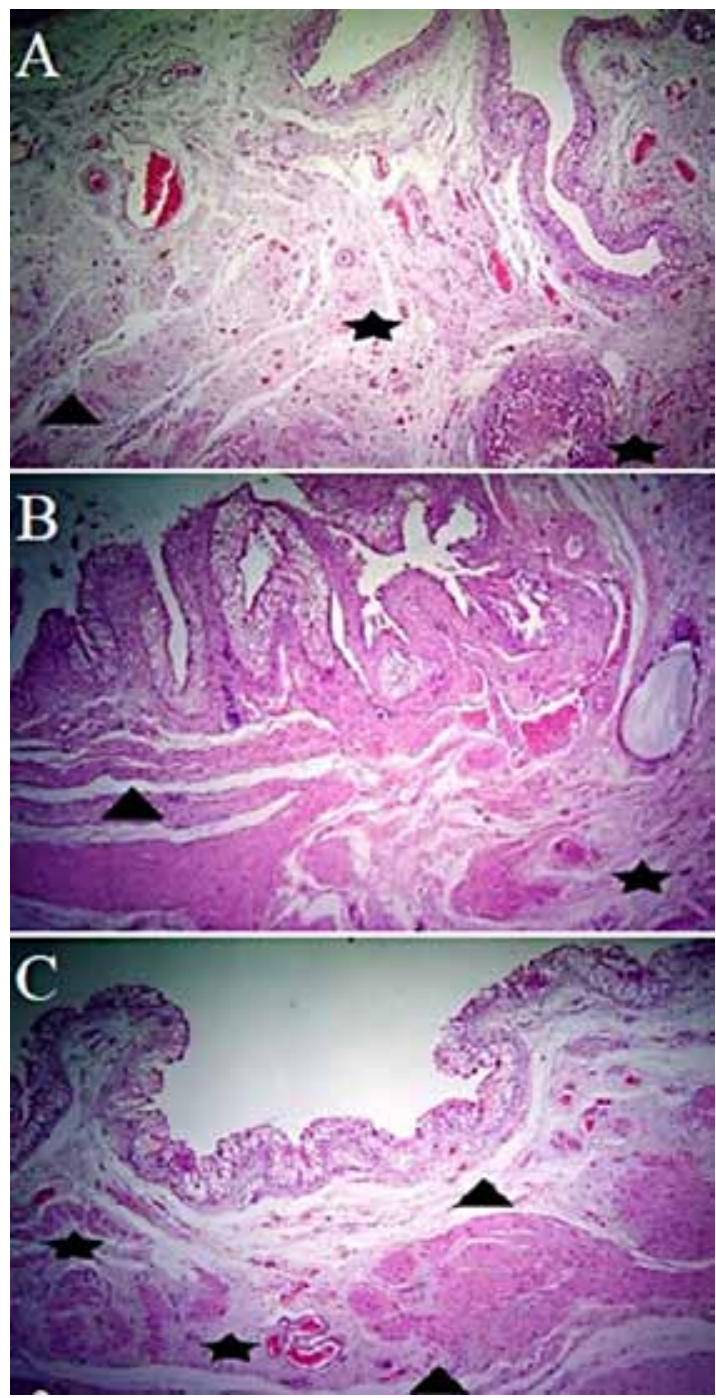

Fig. 7A,B,C. Haematoxylin and eosin staining. Stars: Graft applied region. Triangle: Urinary bladder, $\times 4$. (A: Group 1, B: Group 2, C: Group 3) 


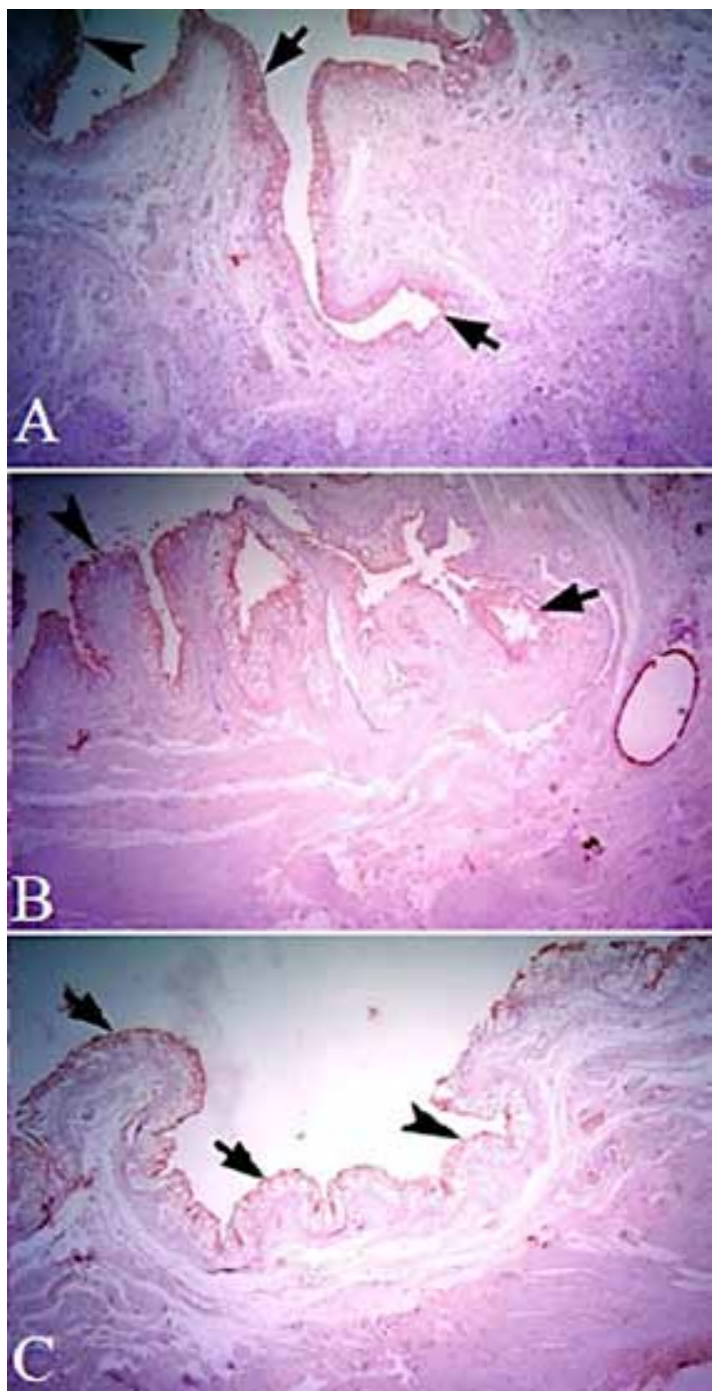

Fig. 8A,B,C. Cytokeratin staining. Arrowhead: Urinary bladder epithelial tissue. Arrow: Newly formed epithelial tissue in the graft region, $\times 4$. (A: Group 1, B: Group 2, C: Group 3) 

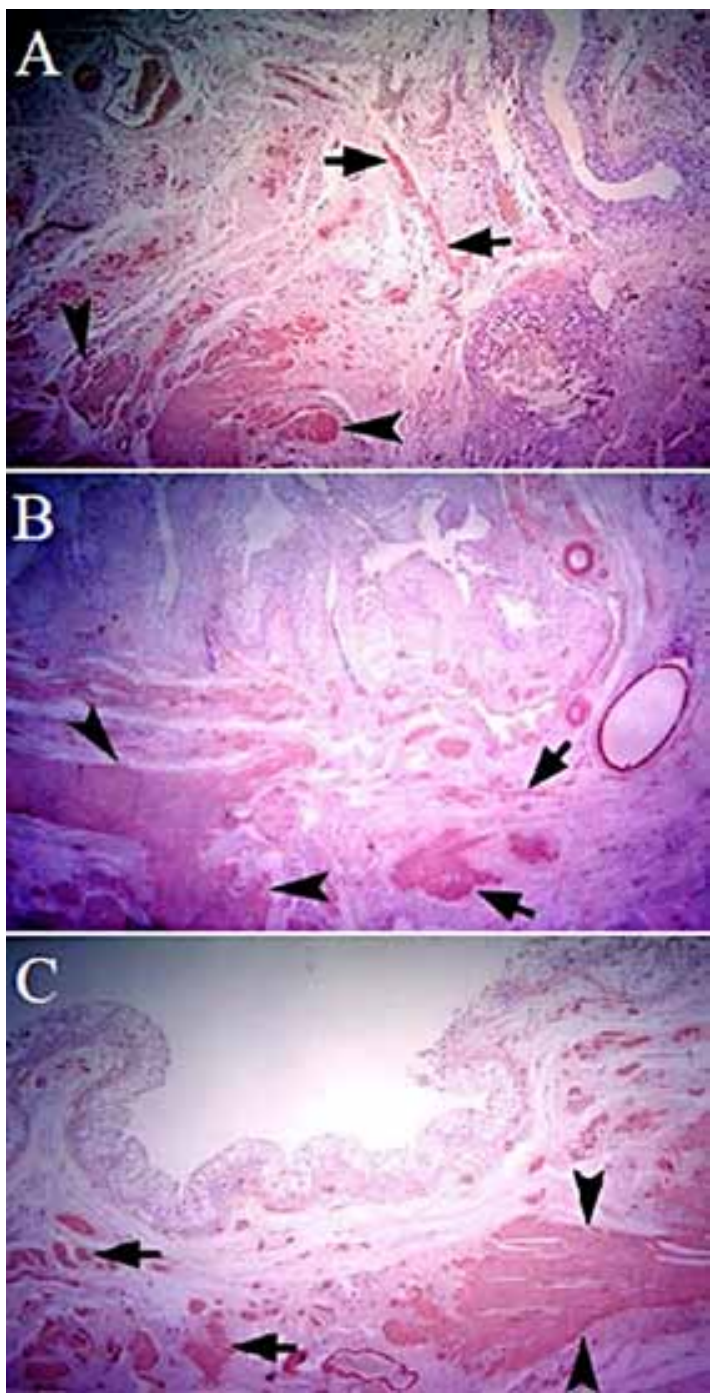

Fig. 9A,B,C. Alpha smooth actin staining. Arrowhead: Urinary bladder smooth muscle. Arrow: Newly formed smooth muscle in the graft region, ×4. (A: Group 1, B: Group 2, C: Group 3) 